\title{
ATIVIDADE DE EXTRATOS ETANÓLICOS SOBRE O CRECIMENTO “IN VITRO” DE COLLETROTRICHUM MUSAE
}

\author{
Bruna Carminate ${ }^{1}$ \\ Winicius Botelho de Souza ${ }^{2}$ \\ Bianca Ferreira Santos ${ }^{3}$ \\ Tatiana Fiorotti Rodrigues ${ }^{4}$ \\ Marcelo Barreto da Silva ${ }^{5}$
}

Resumo: Diversas doenças afetam a qualidade das frutas na fase pós-colheita, como a antracnose, doença ocasionada pelo fungo Colletotrichum musae no fruto de banana. A utilização de fungicidas de origem vegetal poderá constituir um método alternativo e promissor no controle de doenças. Assim, o objetivo deste trabalho foi avaliar a atividade de extratos vegetais de Eugenia astringens Cambess no controle in vitro do fungo fitopatogênico C. musae. O extrato etanólico foi obtido a partir de folhas e sementes de $E$. astringens por maceração e realizado a triagem fitoquímica. Os fitocompostos encontrados foram alcalóides, saponina, flavonóis, fenóis e taninos, esteróides, terpenos e cumarinas. Os extratos testados apresentaram atividade significativa no crescimento do C. musae, onde o extrato obtido da semente reduziu em $50 \%$ o crescimento radial micelial do fungo. Os extratos testados apresentam alternativa promissora no controle da antracnose de banana pós-colheita.

Palavras-chave: Triagem fitoquímica; Controle biológico; Antracnose; Banana.

\footnotetext{
${ }^{1}$ Agronomia/Universidade Federal do Espírito Santo, Centro Universitário Norte do Espirito Santo, Brasil. E-mail: brunabcarminate@hotmail.com.

${ }^{2}$ Agronomia/Universidade Federal do Espírito Santo, Centro Universitário Norte do Espirito Santo, Brasil. E-mail: winicius07@hotmail.com.

${ }^{3}$ Agronomia/Universidade Federal do Espírito Santo, Centro Universitário Norte do Espirito Santo, Brasil. E-mail: biancasantos123@hotmail.com.

${ }^{4}$ Agronomia/Universidade Federal do Espírito Santo, Centro Universitário Norte do Espirito Santo, Brasil. E-mail: tati_fiorotti@hotmail.com.

${ }^{5}$ Professor Titular/Universidade Federal do Espírito Santo, Centro Universitário Norte do Espirito Santo, Brasil. E-mail: marcelobarretodasilva@gmail.com.
} 